\title{
EL PENSAMIENTO POLÍTICO EN LA NARRATIVA HISTORIOGRÁFICA MEDIEVAL. EL CASO DE LA CRÓNICA NAJERENSE
}

POLITICAL THOUGHT IN MEDIEVAL HISTORIOGRAPHIC NARRATIVE.

THE CASE OF THE NAJERENSE CHRONICLE

\author{
André González Mayo * \\ andregonzalez.mayo@gmail.com
}

RESUMEN: Este artículo pretende analizar una narración historiografíca medieval, la Crónica Najerense, desde los presupuestos del llamado "Nuevo Medievalismo" y, más concretamente, utilizando la metodología propuesta por la historiadora norteamerica Gabrielle Spiegel. Para ello se realizará una breve aproximación a la novedosa concepción del texto historiográfico, aquella que surge a través de la denominada "Posmodernidad", de la que se sustentará el "Nuevo Medievalismo". Asimismo, se realizará una breve exposición de las bases teóricas y de la metodología empleada para, posteriormente, abordar el análisis del texto. El estudio de la Crónica Najerense se vertebrará entorno a dos cuestiones fundamentales, la utilización de la forma genealógica en la obra y la adopción por parte de la primera historiografía castellana del viejo discurso "neogótico". Para concluir, se tratará de poner en relación todas estas cuestiones y se resaltará la importancia de las narraciones historiográficas a la hora de acercarse al pensamiento político medieval.

Palabras Clave: "Nuevo Medievalismo", Narración, "Lógica social del texto", Crónica Najerense, "Neogoticismo".

ABSTRACT: This article aims to analyze a medieval historiographical narrative, the Najerense Chronicle, from the budgets of the so-called "New Medievalism" and, more specifically, using the methodology proposed by the American historian Gabrielle Spiegel. For this, a brief approach to the novel conception of the historiographic text will be carried out, the one that arises through the so-called "Postmodernity", which will support the "New Medievalism". Likewise, there will be a brief presentation of the theoretical bases and the methodology used to subsequently address the analysis of the text. The study of the Najerense Chronicle will be based on two fundamental questions, the use of the genealogical form in the work and the adoption by the first Castilian historiography of the old "neo-Gothic" discourse. To conclude, we will try to relate all these questions and highlight the importance of historiographical narratives when approaching medieval political thought.

KeYWORDS: "New Medievalism", Narrative, "Logic social of the text", Chronicle Najerense, "Neogoticism".

\section{Introducción}

El presente trabajo pretende analizar un texto historiográfico medieval, la comúnmente denominada Crónica Najerense, una narración compuesta a finales del siglo XII, entre los años 1185 y 1194, en el reino de Castilla. Para ello se tomará como punto de partida algunas de las teorías asociadas a la llamada "Posmodernidad", especialmente aquellas que defienden la naturaleza exclusivamente narrativa del texto historiográfico. Entre algunas de estas se encuentran las tesis del historiador norteamericano Hayden White, que defienden la

\footnotetext{
* Máster en Estudios Medievales Europeos de la Universidad de Santiago de Compostela. Investigador especializado en historia medieval.
} 
gran proximidad a nivel formal y metodológico entre la historia y la literatura. La concreción de estos nuevos planteamientos en la historiografía reciente dio lugar en los años noventa al llamado "nuevo medievalismo". Una nueva corriente historiográfica que apuesta por un acercamiento al texto historiográfico medieval desde una perspectiva posmoderna. Entre algunas de las metodologías desarrolladas se encontraría la llamada "lógica social del texto", propuesta por la historiadora norteamericana Gabrielle Spiegel (1990, p. 59-86). Esta nueva metodología analiza la forma literaria del texto historiográfico, que será un producto siempre del contexto histórico en que la obra se articula y, por lo tanto, profundiza en la estrecha relación entre texto y contexto. Esta metodología será la empleada en el presente para el estudio de esta particular narración, lo que permitirá identificar el texto, aunque solo sea a nivel formal, con la tipología de las genealogías históricas. Una de las principales preocupaciones del autor será la adopción del discurso "neogoticista" en la historiografía castellana, lo que permite legitimar la naciente monarquía castellana y la figura de su principal valedor, el monarca Alfonso VIII (1158-1214), en torno a una cuestión fundamental, el linaje. Por este motivo, la asimilación entre esta obra y la tipología de las genealogías parece bastante evidente. $Y$ es que través de este texto no solo se pretende construir la legitimidad del monarca, sino también prestigiar su linaje frente a sus principales adversarios políticos, así como asegurar su preeminencia política en el fragmentado espacio político peninsular. Sin olvidarse de la necesidad de legitimación de las recientes políticas expansivas protagonizadas por el reino castellano. Por este motivo, la Crónica Najerense se presentará como un testimonio perfecto para acercarse al pensamiento político en la Edad Media, pero, sobre todo, para comprobar la estrecha relación de dependencia entre la política y la historia en la época medieval.

\section{La naturaleza narrativa de la historia}

A lo largo de las últimas décadas del siglo pasado, fundamentalmente a partir de los años setenta, se ha venido produciendo un replanteamiento o una reformulación dentro de la disciplina histórica en general. El cambio se ha hecho notar y se puede apreciar en el nuevo "modo de concebir, interpretar y escribir la historia" (AURELL I CARDONA, 2006a, p. 811). Esta transformación no sería posible sin la irrupción de nuevas ideas, la gran mayoría vinculadas a 
la comúnmente denominada Posmodernidad, en la que las nuevas corrientes filosóficas y algunos autores, los llamados "posmodernos", tendrán un papel fundamental. ${ }^{1}$

Uno de estos autores es el historiador norteamericano Hayden White, cuyo pensamiento ha cuestionado la capacidad del historiador para acceder al pasado, al menos para hacerlo de una manera racional y objetiva, tal y como se había venido pensando hasta ahora (AURELL I CARDONA, 2006b, p. 627). El historiador lo único que podría hacer es representar el pasado, o en palabras de Frank Ankersmit, "hacer de nuevo presente algo ausente" (BOLAÑOS DE MIGUEL, 2011, p. 274). La imposibilidad del historiador para acceder a una realidad pasada y que, por su propia naturaleza finita, no solo no existe, sino que además no se puede observar ni experimentar con ella, ya que a nuestra disposición solo tenemos los restos que ese pasado ha dejado(BOLAÑOS DE MIGUEL, 2011, p. 275), ${ }^{2}$ impediría la que durante mucho tiempo fue la máxima del historiador positivista, el descubrimiento de la verdad. Aquello que "el historiador presenta como una descripción imparcial del pasado, es en verdad una construcción de los propios historiadores" (BOLAÑOS DE MIGUEL, 2011, p. 274). De este modo, el único método del que dispondría el historiador para recuperar el pasado, para representarlo, es la construcción de un relato(AURELL I CARDONA, 2006b, p. 627).

Esta tesis llevó a Hayden White a considerar a "la obra histórica como lo que más visiblemente es: una estructura verbal en forma de discurso en prosa narrativa" (WHITE, 1992, p. 9). Además, la simple exposición de los acontecimientos históricos no dice nada al lector, ni siquiera la ordenación cronológica de los mismos, como muy bien advertía Hayden White, puesto que para que los acontecimientos o la crónica - la ordenación cronológica de los acontecimientos- adquiera un carácter explicativo, tiene que ser a través de su integración y su empleo en la construcción de un relato(WHITE, 2003a, p. 111-112). Pero no solo eso, sino que además

los acontecimientos son incorporados en un relato mediante la supresión y subordinación de algunos de ellos y el énfasis en otros, la caracterización, la repetición de motivos, la variación del tono y el punto de vista, las estrategias descriptivas alternativas y similares; en suma, mediante todas las técnicas

\footnotetext{
${ }^{1}$ El postestructuralismo de Foucault, el deconstruccionismo de Derrida, la nueva hermenéutica de Paul Ricoeur y Michel de Certeau, el formalismo historicista de Hayden White y todas las derivaciones asociadas al giro lingüístico, sistematizadas por Richard Rorty (AURELL I CARDONA, 2006A, p. 811).

${ }^{2}$ Enrique Moradiellos (2013, p. 27) denomina a estos restos y vestigios del pasado que perviven en el presente en la forma de residuos materiales, huellas corpóreas y ceremoniales: "Reliquias del pasado".
} 
que normalmente esperaríamos encontrar en el tramado de una novela. (WHITE, 1992, p. 113).

Este proceso compositivo es lo que Hayden White llamaría "tramado", ${ }^{3}$ y que P. Ricoeur explicaría recurriendo al viejo término aristotélico del mythos, o "la composición de los hechos". El mythos sería la operación en la que disponemos a los acontecimientos y los dotamos de un principio, nudo y desenlace, a través del cual el texto se hace inteligible para el lector (RICOEUR, 2000, p. 191). El criterio a la hora de seleccionar el tipo de trama es de naturaleza estética o moral, al igual que el efecto explicativo que se conseguiría a través de la trama (WHITE, 2003b, p. 244). ${ }^{4}$ Por lo tanto, la labor del historiador dependería en gran medida de su propia imaginación, la que Collingwood calificó como "imaginación constructiva", ${ }^{5}$ y que llevaría a Hayden White a afirmar que:

Ha habido una resistencia a considerar las narraciones históricas como lo que manifiestamente son: ficciones verbales cuyos contenidos son tan inventados como descubiertos, y cuyas formas tienen más en común con sus formas análogas en la literatura que con sus formas análogas en las ciencias (AURELL I CARDONA, 2006b, p. 627).

Sin embargo, esta asimilación entre historia y literatura se produciría únicamente a nivel formal y metodológico, sin que ello suponga un cuestionamiento del estatus epistemológico de la historia. El historiador norteamericano era muy consciente de que la historia remite siempre a una realidad que tiene un referente externo, mientras que la literatura únicamente se bastaría con una realidad "intratextual” (AURELL I CARDONA, 2006b, p. 632). Y es que en la historia, "los acontecimientos que constituyen la línea narrativa no son producto de la imaginación del historiador, sino que están confirmados por pruebas, o al menos se supone que debe poder deducirse su verosimilitud a partir de lo que consta explícitamente en los documentos" (WHITE, 2003b, p. 242), algo que no ocurre

\footnotetext{
3 Por "tramado" entendía Hayden White "la codificación de los hechos contenidos en las crónicas como componentes específicos de estructuras de trama" (WHITE, 2003a, p. 112). La trama no explica los acontecimientos, sino que explica el relato, ya que permitiría identificar el texto con un tipo de relato reconocible culturalmente y gracias a ello alcanzar el efecto explicativo deseado (WHITE, 2003b, p. 243-246).

${ }^{4}$ De una manera similar fueron interpretadas las narraciones historiográficas, que consideraba que las "únicas bases para preferir una interpretación a otra son morales o estéticas, no teóricas o científicas" (BOLAÑOS DE MIGUEL, 2011, p. 285).

${ }^{5}$ Esta imaginación constructiva le permite a Collingwood equiparar al historiador y al detective, quién basándose en las evidencias disponibles, siempre fragmentarias, le permitirá formularse las preguntas correctas. Además, esta funcionaría de manera semejante a la imaginación a priori de Kant, gracias a la cual aun cuando no se vean los dos lados de la mesa de manera simultánea, se puede afirmar que tiene dos lados, porque "el concepto mismo de un lado implica al menos otro lado (WHITE, 2003a, p. 112).
} 
necesariamente en la literatura. A pesar de ello, esto no supone que no se puedan aplicar algunos de los métodos de la teoría literaria al estudio de obras historiográficas, del modo en que Hayden White lo hizo en su célebre obra: Metahistoria. La imaginación histórica en la Europa del siglo XIX.

\section{La elección de una metodología de trabajo}

La concreción de las ideas de la Posmodernidad en el campo del estudio de la Edad Media, aunque de manera especial al análisis de los textos historiográficos medievales, dio lugar a comienzos de los años noventa al llamado: "Nuevo Medievalismo" (BROWNLEE; BROWNLEE; NICHOLS, 1991). ${ }^{6}$ Esta corriente de investigación apuesta por un acercamiento a los "documentos como textos, dejando de considerarlos como fuentes neutras desde una perspectiva intencional e ideológica" (AURELL I CARDONA, 2006a, p. 811). Esta novedosa concepción de los textos historiográficos originó nuevas metodologías, algunas de ellas de gran interés para el estudio de las crónicas medievales. Es preciso destacar la desarrollada por Gabrielle M. Spiegel, la que pretende ahondar en la llamada "lógica social del texto", que será la empleada en el presente estudio de la Crónica Najerense. Al ocupar el texto historiográfico un determinado espacio social, sería, por lo tanto, producto del mundo social de su autor a la vez que un agente textual al servicio de ese mismo mundo (SPIEGEL, 1990, p. 77). ${ }^{7}$ A partir de la consideración de la historia como un artefacto literario, Gabrielle M. Spiegel apuesta por un análisis de las formas literarias de la historiografía, poniendo un especial énfasis en sus transformaciones, que serán fruto de los cambios tanto políticos como sociales del contexto en que se articulan, así como transformadores de esa realidade (AURELL I CARDONA, 2006a, p. 822). Esta metodología se fundamentará, por lo tanto, en la estrecha relación de dependencia entre el texto y el contexto histórico. Por ese motivo, se pondrá especial interés en el análisis de la forma y sus variaciones, sin olvidarse, por supuesto, del contenido de la obra, y poniéndolo en relación con el contexto que la origina.

\section{La Crónica Najerense}

\footnotetext{
${ }^{6}$ Es indispensable el artículo de Aurell i Cardona (2006a). Igualmente, para apreciar la radical diferencia entre un medievalismo heredero de las ideas del positivismo e historicismo decimonónico frente a un medievalismo que surgirá de la renovación intelectual asociada a la postmodernidad, se puede ver: P. Freedman y G. M. Spiegel (1998).

7 Desde esta perspectiva, los textos historiográficos deberían ser estudiados en su doble dimensión, como espejos de la sociedad y como generadores de las realidades sociales (AURELL I CARDONA, 2016, p. 123).
} 
Esta obra historiográfica medieval fue escrita en el reino castellano a finales del siglo XII, en pleno reinado de Alfonso VIII. Generalmente, se la considera la primera narración historiográfica castellana, ${ }^{8}$ por lo que su autor, que pertenece en el anonimato a lo largo de toda la obra, debió de ser natural de ese mismo reino. ${ }^{9}$ Menéndez Pidal planteó la posibilidad de que debería de tratarse de un clérigo del monasterio de Santa María de Nájera, o por lo menos alguien afecto a él (MENÉNDEZ PIDAL, 1923, p. 332). ${ }^{10}$ Este cenobio ubicado en la ciudad de Nájera se encuentra en tierras riojanas. Un territorio - el de Nájera - que desde el reinado de Alfonso VII pasó a formar parte de manera definitiva del reino castellano. Asimismo, la gran presencia de relatos de carácter legendario, procedentes muchos de ellos de la tradición oral y de la primitiva tradición épica castellana y literaria, podrían evidenciar nuevamente el origen castellano de la obra (MENÉNDEZ PIDAL,1923, p. 331-332). En un estudio reciente, Reglero de la Fuente se pronunció a este respecto y añadió que además de la procedencia najerense de su autor, este debió de guardar algún tipo de vínculo con la corte del monarca (REGLERO DE LA FUENTE, 2009). Solo esta proximidad explicaría el deseo del autor de exaltar la monarquía castellana, como advirtió Reglero de la Fuente y como se verá a lo largo de las páginas siguientes. Sin olvidar la estrecha vinculación existente entre historia y política en la Edad Media, puesto que en palabras de Menghello Matte (2009, p. 11): "La historia y la política estaban fuertemente ligadas en una relación simbiótica, en la que el cronista sustentaba intelectualmente el sistema, mientras que a su vez era beneficiado por el monarca o su corte".

La cuestión de su cronología es mucho más compleja, fundamentalmente debido a la ausencia de referencias explícitas del autor que nos remitan a la fecha exacta de su composición. Una carencia que podría evidenciar el carácter inacabado de la obra. ${ }^{11}$ Sin embargo, la mayoría de estudios recientes se han puesto de acuerdo y han situado la redacción de la obra a finales de la centúria (UBIETO ARTETA, 1985, p. 30; ESTÉVEZ SOLA,

\footnotetext{
${ }^{8}$ Decía G. Le Morvan (2009; 2013) que esta obra "marca un punto de inflexión en la escritura historiográfica penínsular, pues se trata de la primera crónica real verdaderamente castellana".

${ }^{9}$ Ubieto Arteta (1966, p. 26-29) planteó la posibilidad de que su autor sea de origen francés, sin embargo, aunque no se debe descartar esta hipótesis, parece poco.

10 Las constantes alusiones y noticias referentes al cenobio najerino permitieron a este autor sostener esta hipótesis, que no ha sido cuestionada hasta la actualidad.

${ }^{11}$ El primero en contemplar esta posibilidad fue Estévez Sola (1995B, p. LXVII), aunque no se atreve a afirmar esta hipótesis de manera categórica Sin embargo, un firme defensor de esta hipótesis es Catalán Menéndez-Pidal (2001, p. 868).
} 
1995A, p. 94-103). Incluso algunos autores como Bautista Pérez (2009a; 2010) han precisado todavía más en esta cuestión, proponiendo una cronología tardía que oscilaría entre los años 1185-1194 (BAUTISTA PÉREZ, 2019). Por lo tanto, su redacción se produciría en un momento de gran esplendor político del reino castellano, que gozaría de una posición prácticamente hegemónica entre los reinos cristianos peninsulares, resultado de una agresiva política militar (RUIZ GÓMEZ, 2013, p. 157-158).

\section{La "lógica social" de la Crónica Najerense}

Anteriormente se ha mencionado que la intención del presente trabajo es ahondar en la "lógica social del texto", la metodología propuesta por G. Spiegel, y que profundiza en el estudio de la forma literaria del texto historiográfico. Asimismo, pone especial hincapié en la estrecha relación existente entre texto y contexto. Una vez aclaradas estas cuestiones, el análisis de la forma literaria de esta narración historiográfica nos remite de manera ineludible a la clasificación tipológica que establece Aurell i Cardona para los distintos géneros historiográficos (AURELL I CARDONA, 2013, p. 95-141, de manera especial p. 109-118). De este modo, la Crónica Najerense se correspondería con el género de las llamadas "crónicas universales", una variedad tipológica muy cultivada a lo largo de la Edad Media, pero de manera muy especial en el siglo XII (AURELL I CARDONA, 201). ${ }^{12}$ Sin embargo, uno de los intereses centrales de su autor, como muy bien expresa Bautista Pérez (2009b/2010), es "incorporar el discurso neogótico a la historiografía castellana",13 lo que lleva a una reinterpretación del texto y a su identificación con el género de las genealogias. ${ }^{14}$

El nacimiento de este nuevo género historiográfico se produjo entre los siglos XI y XII, aunque su difusión se limitó únicamente a algunas regiones concretas de Europa occidental, entre las que figuraban Flandes, Francia y Cataluña (AURELL I CARDONA, 2013, p. 112). En la Península Ibérica habría que esperar hasta los inicios del siglo XIII y el XIV para su aparición y

\footnotetext{
${ }^{12}$ La narración abarcaría, como es natural en este tipo de obras, desde los orígenes bíblicos hasta la actualidad, en este caso la muerte de Alfonso VI.

${ }^{13}$ F. Bautista Pérez, "Genealogía y leyenda. El surgimiento de los reinos de Castilla y Aragón”, e-Spania (en línea), no 7, junio, 2009B. Publicado el 16 agosto 2010, consultado el 11 agosto 2019. URL: http://journals.openedition.org/e-spania/18086; DOI: 10.4000/e-spania.18086.

${ }^{14}$ Aurell i Cardona (2013, p. 109) advertía de la gran permeabilidad entre las distintas variedades tipológicas y la dificultad muchas veces de clasificar las distintas obras.
} 
definitiva consolidación, ${ }^{15}$ por lo que su adopción en la Crónica Najerense sería algo novedoso en la historiografía medieval hispana. No obstante, los cambios formales de la escritura histórica representan algo más que un simple cambio de estilo, puesto que son simultáneamente la causa y la consecuencia de una transformación mucho más profunda en la estructura social. Anteriormente, se ha mencionado que el texto historiográfico ocupa un determinado espacio social, que es siempre fruto de un determinado contexto histórico, pero que a la vez tiene la capacidad de incidir en ese mismo contexto. Esto es lo que G. Spiegel ha denominado la "lógica social del texto" (AURELL I CARDONA, 2016, p. 27). Por lo tanto, la aparición y difusión de este nuevo género historiográfico es el resultado de unas transformaciones mucho más profundas en la sociedad que las origina. A este respecto, decía Aurell, "las genealogías se divulgan en Europa durante la segunda mitad del siglo XII como un instrumento privilegiado para consolidar el poder monárquico, basado en la transmisión dinástica y hereditaria" (AURELL I CARDONA, 2016, p. 29). ${ }^{16}$ Por lo tanto, la composición de la Crónica Najerense, pero, sobre todo, la adopción de la forma de las genealogías estaría estrechamente relacionada con el nacimiento de la "monarquía feudal" en el reino de Castilla. ${ }^{17}$

En el siglo XII, las nacientes dinastías monárquicas necesitaban consolidar su creciente poder, por lo que la elaboración de textos historiográficos podría ser un método muy eficaz para dicho fin. De este modo, las narraciones historiográficas permitieron a las distintas monarquías medievales legitimar una agresiva política expansiva. Igualmente, le proporcionaban no solo un gran prestigio social al linaje en cuestión, sino que también la preeminencia política frente a sus principales adversarios políticos(AURELL I CARDONA, 2016, p. 16). Hay que tener en cuenta que muchos de estos linajes regios acababan de alcanzar este

\footnotetext{
${ }^{15}$ I. Beceiro Pita, "La conciencia de los antepasados y la gloria del linaje en la Castilla bajomedieval" en Pastor de Togneri, R., Relaciones de poder, de producción y parentesco en la Edad Media y Moderna, Madrid: Centro Superior de Investigaciones Científicas, 1990, p. 330.

${ }^{16}$ A partir del siglo XI, los cambios que se produjeron en la estructura familiar medieval, asociados a la aparición de la denominada organización agnática de la familia, privilegiaron la figura del primogénito varón en la transmisión hereditaria del patrimonio nobiliar (SPIEGEL, 1990, p. 78). Estas transformaciones estructurales estaban, indudablemente, asociadas a la patrimonialización del poder y de las propiedades aristocráticas (BECEIRO PITA, 1990, p. 330). Evitando la fragmentación de la herencia, se buscaba acrecentar el poder de las grandes familias nobiliarias. Las genealogías surgen como una reconstrucción de la línea de transmisión hereditaria del patrimonio familiar. Gracias a su gran desarrollo en estos siglos, el linaje y, por lo tanto, la sangre, se convirtió en una fuente de prestigio social y de preeminencia política dentro de las élites aristocráticas (SPIEGEL, 1990, p. 78). Este proceso contribuiría en gran medida al nacimiento de la llamada "monarquía feudal". ${ }^{17}$ A este respecto se puede consultar: C. Estepa Díez (2011a, p. 11-63).
} 
nuevo estatus político recientemente, por lo que necesitarían del enorme peso del pasado para su legitimación permanente. Decía Spiegel $(1997$, p. 85$)$ que en una sociedad como la medieval, que sentía una actitud piadosa y reverencial hacia el pasado, se necesitaba buscar en ese mismo pasado la explicación y legitimación de cada desviación de la tradición. ${ }^{18}$ Así, la aparición de un nuevo linaje regio necesitará de la elaboración de un relato historiográfico que lo respalde. Al igual que ocurriría con el nacimiento de un nuevo reino. De este modo, las "nacientes monarquías buscaran establecer una genealogía, real o imaginaria, que les permita conectar con los orígenes legendarios de la dinastía y, en concreto, de los fundadores" (AURELL I CARDONA, 2016, p. 19). No importa, en absoluto, que la relación de parentesco con el antepasado en cuestión sea de dudosa autenticidade (BECEIRO PITA, 1990, p. 336). ${ }^{19}$ La mayor antigüedad del linaje le conferirá una mayor autoridad y prestigio social al linaje, "en un mundo donde el peso de la tradición es enorme" (AURELL I CARDONA, 2013, p. 103). Las genealogías se presentarán, por lo tanto, como un poderosísimo procedimiento que permitirá conectar un pasado remoto con un presente frágil y que, además, es preciso legitimar. Por consiguiente, los Capetos conectaron sus orígenes legendarios con la monarquía troyana, los reyes astur-leoneses y posteriormente los castellanos, en cambio, enlazaron con la monarquía visigótica (AURELL I CARDONA, 2016, p. 28). Es muy frecuente, por lo tanto, el recurso a la falsificación, la manipulación histórica, la invención y la inclusión de relatos ficticios de naturaleza legendaria en este tipo de narraciones genealógicas.

A finales del siglo XII, Alfonso VIII era uno de los monarcas cristianos más poderosos de la Península Ibérica. Los límites territoriales de su reino, Castilla, habían sido ampliados gracias a una agresiva política militar, por lo que rápidamente se convirtió en el objetivo de sus principales rivales políticos. A pesar de su creciente poder, la reciente dinastía fundada hace poco más de un siglo por su antepasado, Fernando I (1029-1065), carecía del prestigio necesario para ejercer la posición de liderazgo que el monarca anhelaba, que la cancillería

\footnotetext{
${ }^{18}$ Decía Aurell que en una sociedad tan tradicional como la medieval, "los hábitos que superan el paso del tiempo y consiguen establecerse en el presente adquieren influjo mucho mayor que las novedades (...) los gobernantes medievales basaban buena parte de la autoridad de su poder en la autoridad del pasado" (AURELL I CARDONA, 2016, p. 24). "Ningún avance es seguro si no está garantizado por un precedente en el pasado", decía Le Goff (1999, p. 292).

${ }^{19}$ Esta tendencia a la falsificación se hizo patente en la Castilla del siglo XIII y XIV, en donde era habitual que la mayoría de los principales linajes nobiliarios establecieran como fundador del linaje a personajes míticos tales como el Cid o el Conde Fernán González.
} 
regia quería proyectar. ${ }^{20}$ Además, la historia del reino de Castilla era una historia reciente, por lo que necesitará que se construya de la pluma de algún cronista de la corte.

Originariamente, el condado de Castilla había estado integrado en el reino de León, al menos teoricamente (ESTEPA DÍEZ, 2009, p. 39). También es muy difícil precisar el momento exacto en que el territorio castellano dejó de ser un condado para convertirse en un reino, fundamentalmente debido al fuerte sesgo ideológico de las fuentes. ${ }^{21} \mathrm{~A}$ excepción de un breve periodo de tiempo que coincide con el reinado de Sancho II (1065-1072), el condado de Castilla no alcanzaría la definitiva categoría de reino y, por lo tanto, una independencia efectiva del reino de León, hasta la muerte de Alfonso VII (1126-1157). Esto sitúa el nacimiento de este reino en el reinado de Alfonso VIII (MARTíNEZ DÍEZ, 2005, p. 11-13).

El fallecimiento del emperador en el año 1157 supuso la división del reino entre sus dos hijos, Sancho III (1157-1158) heredó el reino de Castilla mientras que Fernando II (11571188) heredó el reino de León. La prematura muerte de Sancho III, tan solo un año después de acceder al trono, dejo a un regente al frente del reino, pues su hijo, el joven Alfonso, carecía de la edad necesaria para gobernar. Sin embargo, unos años después y tras hacer frente a una serie de agresiones externas durante su minoría de edad, el chico había alcanzado la edad adulta y se convirtió en Alfonso VIII. Este monarca no solo recuperó los territorios que le habían sido arrebatados, sino que además amplió de una manera sustancial los límites del reino. A consecuencia de esta creciente actividad bélica, el reino de Castilla restableció su dominio sobre la ciudad de Toledo; el infantazgo Tierra de Campos, un polémico y muy disputado territorio situado en los difusos límites fronterizos entre el reino de Castilla y el reino de León; restablecería su control sobre los territorios riojanos; engrandecería el reino a través de nuevas conquistas frente a los musulmanes, entre las que destaca la toma de Cuenca; y conquistaría algunas poblaciones de la Transierra leonesa, entre las que se

\footnotetext{
${ }^{20}$ La cancillería regia desarrolló un programa propagandístico destinado a exaltar la figura de Alfonso VIII y presentarlo como líder de la Cristiandad. Su símbolo de identidad fue la cruzada, que vendría acompañado de una serie de campañas militares contra los musulmanes, convirtiéndolo en una especie de paladín de la fe cristiana, que, a su vez, se vio favorecido por sus excelentes relaciones con el papado. Ver: C. de Ayala Martínez, "Alfonso VIII. Cruzada y Cristiandad", Espacio, tiempo y forma, no 29, 2016, pp. 75-113.

${ }^{21}$ Estepa Díez (2009, p. 40) cree que el primer rey de Castilla fue Sancho Garcés III. También cree que Fernando I heredó el título de conde de Castilla, pero que no fue hasta que asumió el gobierno del reino de León, a la muerte de su cuñado Vermudo III, que se convirtió en rey de Castilla y León. Viñayo González $(1999$, p. 36) cree que fue mucho antes. Según este autor, después de la muerte de su padre, Fernando I asumió el título de rey de Castilla).
} 
encuentra la ciudad de Trujillo. ${ }^{22}$ Sin embargo, esta preeminencia castellana pronto se verá amenazada por las alianzas entre los reinos de Navarra y Aragón a finales de 1190, y Portugal y León a comienzos de 1191, una alianza que se consumará con el matrimonio entre el rey de León y la infanta portuguesa. Sin olvidar la confederación portuguesa, leonesa y aragonesa, que desde la primavera de 1191se forma para hacer la guerra a Castilla (GONZÁLEZ GONZÁLEZ, 1960, p. 709-710).

Esta preeminencia castellana se vio rápidamente amenazada por el frágil equilibrio político existente entre los distintos reinos peninsulares. En este delicado momento se debió de componer esta narración, "una crónica que pretendía afirmar plenamente la dignidad castellana, rivalizando con la prestigiosa historiografía regia astur-leonesa y justificando, en contra de sus tesis históricas, la pretensión a ejercer una hegemonía pan-hispánica" (MARTIN, 2009/2013).

La reciente historia del reino de Castilla, la ausencia de una historiografía propia que legitimara las recientes y las futuras conquistas militares, era un gran impedimento para los planes futuros del joven rey. ${ }^{23} \mathrm{~A}$ este respecto, decía Spiegel que en una sociedad tradicional como la medieval, la política del presente dependía constantemente del pasado para su sostenimiento (SPIEGEL, 1997, p. 83). Por este motivo, la actividad de los historiadores será necesaria para legitimar la actividad política de sus gobernantes. Esta utilidad eminentemente política de la historia explica el enorme uso de falsificaciones, leyendas y mitos en las narraciones historiográficas (SPIEGEL, 1997, p. 85), lo que además se verá favorecido por la ausencia de crítica textual, al menos tal y como la entendemos hoy en día. ${ }^{24}$ Sin olvidarnos, por supuesto, del carácter claramente ficticio que posee toda narración historiográfica, ya sea medieval, moderna o posmoderna. En ese momento, un monje del monasterio de Nájera, posiblemente muy próximo a la persona del rey o, al menos, a la corte regia, y sensible a las tendencias historiográficas de la época, decidió escribir la Crónica Najerense. El recurso a la

\footnotetext{
22 Para profundizar en estas cuestiones, ver: J. González González (1960); G. Martínez Díez (1995). Para un acercamiento más sintético de esta cuestión: I. Álvarez Borge (2003, p. 137-140).

${ }^{23}$ El reino de Castilla carecía de una memoria histórica, a no ser la procedente de la tradición oral. Por ese motivo, García de Cortázar (1992, p. 173-175) resalta la función de la Crónica Najerense y del Poema de Mio Cid en la fijación por escrito de una memoria colectiva castellana.

${ }^{24}$ Decía Orcastegui y Sarasa que a la hora de seleccionar sus fuentes, los historiadores medievales preferían "lo que habían visto y conocido personalmente, lo que habían podido escuchar de sus contemporáneos y lo que fundamentalmente habían podido leer o consultar directamente de sus antecesores" (C. Orcastegui Gral y E. Sarasa Sánchez, La historia en la Edad Media. Historiografía e historiadores en Europa Occidental: siglos V-XIII, Madrid, Cátedra, 1991, p. 44).
} 
forma genealógica, ${ }^{25}$ así como la adopción del discurso "neogoticista" en la naciente historiografía castellana, evidenciaría dos cuestiones:

1. El deseo de establecer un nexo entre la vieja monarquía visigoda y la recién instaurada dinastía castellana evidenciaría el interés del autor por legitimar, así como prestigiar el linaje de Alfonso VIII. De este modo, el texto najerense pretende resaltar la preeminencia política de la monarquía castellana y de este rey sobre el resto de gobernantes peninsulares, ya que la sangre de los godos correría por las venas del nuevo monarca. ${ }^{26}$

2. El reino de Castilla, al considerarse heredero del reino Visigodo de Toledo, estaría legitimado a llevar a cabo una actividad bélica continuada contra sus rivales, lo que le permitirá expandir sus fronteras y ampliar sus dominios territoriales.

\section{La adopción del discurso "neogoticista"}

Anteriormente se ha hablado de la integración del discurso "neogoticista" en la Crónica Najerense. Pues bien, el "neogoticismo" fue una doctrina política adoptada por el reino astur en tiempos de Alfonso II (760-842), una "modesta entidad política", ${ }^{27}$ en palabras de Mitre Fernández (2009, p. 248), que se consideraba heredero del reino visigodo de Toledo. A través de la recuperación de diferentes manifestaciones ceremoniales, entre las que se encontraban la unción real, el ceremonial palatino o la recuperación del liber judicorum, el reino astur pretendió escenificar la restauración del dominio visigodo de la Península Ibérica (MITRE FERNÁNDEZ, 1999, p. 147). Y es que el joven y humilde reino aspiraba a la "restauración y salvación de Hispania", una "idealizada imagen de unidad territorial que respondía a un mismo credo religioso" (AYALA MARTíNEZ, 2017, p. 209).

\footnotetext{
${ }^{25}$ Anteriormente, se ha dicho que el criterio del historiador a la hora de seleccionar la trama era de naturaleza estética y moral, algo que se podría hacer patente en la elección de la forma, en este caso de la genealógica para la Crónica Najerense. Estética en el sentido de que es sensible a las tendencias historiográficas coetáneas, moral en el sentido de que se adapta a los intereses de la monarquía castellana a la que pretende exaltar.

${ }^{26}$ En un estudio pormenorizado de la literatura genealógica francesa de los siglos XI y XII, Georges Duby (1978, p. 188) concluyó que una de las principales preocupaciones de los textos genealógicos es la legitimación del poder. Su composición estaba ligada a una pretensión de soberanía en momentos en que esta era discutida, como, por ejemplo, probar el derecho de un heredero en el momento de una sucesión discutible.

${ }^{27}$ E. Mitre Fernández, Una primera Europa. Romanos, cristianos y germanos, Madrid: Encuentro, 2009, p. 248. Este joven reino, situado en el norte de la península, estaba protagonizando una intensa actividad bélica frente al Islam. A este respecto ver: C. M. Reglero de la Fuente, "La ocupación de la cuenca del Duero Leonesa por el reino astur", La época de Alfonso III y San Salvador de Valdediós: Congreso de Historia Medieval, Oviedo, 27 de septiembre-2 de octubre, 1993, Oviedo: Servicio de Publicaciones Universidad de Oviedo, 1994, pp.127-150.
} 
Esta ideología política sostenía que los cristianos del norte eran los legítimos herederos del reino visigodo, en lo político y lo religioso, y que "como tales tenían el derecho y la obligación histórica de recuperar aquello que había pertenecido a sus antepasados y que les había sido injustamente arrebatado por los musulmanes" (GARCÍA FITZ, 2006, p. 195). Decía Mitre que "la restauración de ese pasado unitario es inseparable de ciertas aspiraciones hegemónicas" (MITRE FERNÁNDEZ, 2009, p. 250), que responderían, por consiguiente, al intento de afirmar la superioridad de un reino al conjunto de los reinos hispânicos (ÁLVAREZ BORGE, 2010, p. 134). Un deseo de preeminencia que se veía favorecido por la gran fragmentación del espacio político de la Cristiandad. La idea de la restauración era, por lo tanto, una ficción justificadora que legitimaba una acción militar permanente, una política de expansión territorial motivada más por razones socioeconómicas que por el deseo de recuperar unas tierras que le habían sido injustamente arrebatadas García Fitz menciona que hay dos posturas antagónicas para interpretar la "restauración neogótica" o el fenómeno de la "Reconquista". Una es la que defiende la no ruptura y, por lo tanto, la existencia de una continuidad entre el reino visigodo, desaparecido tras la conquista musulmana, y los núcleos cristianos del norte peninsular. La otra es la que sostiene que no existe tal continuidad, que la "restauración neogótica"es una invención, una ficción para justificar una acción militar permanente (GARCÍA FITZ, 2006, p. 195). Nosotros somos partidarios de la segunda interpretación. ${ }^{28}$ Nuevamente se puede ver el enorme poder del pasado, tan necesario en el sostenimiento de la política del presente.

Esta doctrina política fue rápidamente integrada en la historiografía medieval hispana, especialmente en la astur-leonesa. La primera narración historiográfica a la que se incorporó fue la Crónica de Alfonso III (AYALA, 2017, p. 209-210), ${ }^{29}$ una obra propagandística escrita a finales del siglo IX para ensalzar la figura de este monarca. A respecto de esta obra, decía Dacosta Martínez, que el "propósito general de estos relatos es asentar una ficción de continuidad entre el Reino Visigodo de Toledo y el primitivo Reino Astur" (DACOSTA

\footnotetext{
${ }^{28}$ García Fitz menciona que hay dos posturas antagónicas para interpretar la "restauración neogótica" o el fenómeno de la "Reconquista". Una es la que defiende la no ruptura y, por lo tanto, la existencia de una continuidad entre el reino visigodo, desaparecido tras la conquista musulmana, y los núcleos cristianos del norte peninsular. La otra es la que sostiene que no existe tal continuidad, que la "restauración neogótica"es una invención, una ficción para justificar una acción militar permanente (GARCíA FITZ, 2006, p. 195). Nosotros somos partidarios de la segunda interpretación.

${ }^{29}$ Esta narración historiográfica incorporará el discurso neogótico, que estará presente en dos de sus versiones, la Rotense y la Sebastián.
} 
MARTíNEZ, 1992, p. 12). Por este motivo, en este texto, o más bien conjunto de textos, aparecerá por primera vez la figura de don Pelayo, un personaje mítico fundador del reino astur y que, además, lideró la resistencia cristiana frente al Islam (MONTENEGRO VALENTÍN, 2002, p. 112). Al presentar a Pelayo como heredero de los godos, el recién fundado reino Astur sería, por lo tanto, continuador del reino visigodo de Toledo (MONTENEGRO VALENTíN, 2002, p. 112). ${ }^{30}$ Sin embargo, los primeros testimonios que hacen mención a este personaje se compondrán hacía finales del siglo IX, al menos ciento cincuenta años después de que este viviera (ARBESÚ, 2011, p. 323). ${ }^{31}$ Esta distancia temporal acentuará la dimensión mítica del personaje y su utilización claramente política e ideológica en las distintas construcciones historiográficas, que permitirán legitimar la naciente monarquía astur en base a una supuesta continuidad y permanencia visigótica en el nuevo reino. ${ }^{32}$ Esta supuesta continuidad se construirá a través de su persona, de la dinastía que él fundó y de su sangre, y de la que Alfonso III será heredero y continuador. ${ }^{33}$ Una ficción perfectamente construida en los círculos monásticos próximos a la corte. Es interesante, además, la primera aparición de la batalla Covadonga, un episodio pseudo-histórico convertido en hito de la resistencia cristiana frente al invasor musulmán por la actividad de los historiadores. El relato de la batalla narrará la primera gran victoria del ejército cristiano frente a las huestes sarracenas. Lo más sorprendente es el fuerte carácter ficticio de este episodio, que Smith definiría como "una composición eclesiástica religiosamente inspirada", aludiendo a su clara influencia bíblica, pero sobre todo a su carácter más literario que histórico, así como a la gran presencia de elementos de naturaleza sobrenatural y milagrosa (SMITH, 1985, p. 41). ${ }^{34}$

\footnotetext{
${ }^{30}$ Este texto menciona que Pelayo fue nombrado caudillo de los astures por la antigua nobleza visigoda, ahora exiliada en tierras astures, y que a partir de este momento liderará la resistencia cristiana en el norte peninsular. ${ }^{31}$ Este mismo autor advierte también de su tardía aparición en la historiografía árabe, que se produciría hacia el año 1000, lo cual es muy significativo (ARBESÚ, 2011, p. 328).

${ }^{32}$ No es el objetivo de este trabajo discutir acerca de la posible o no historicidad de este personaje, únicamente hacer hincapié en la dimensión claramente mítica y legendaria del mismo en los distintos textos historiográficos medievales.

${ }^{33}$ Decía Aurell i Cardona (2016, p. 46) que este personaje será empleado en las distintas narraciones historiográficas hispanas, tanto las astures, como las leonesas y castellanas, a la hora de construir la legitimidad de los distintos reinos cristianos en base a una supuesta continuidad de la estirpe goda en este personaje y su linaje.

${ }^{34}$ Este episodio tiene un claro origen bíblico, decía Smith que "hay un obispo traidor, Oppa, mientras que Pelayo es un soldado de la Iglesia. Además, cita directamente a David". Pero no solo eso, "el milagro de las piedras lanzadas por las hondas musulmanas que vuelven a caer sobre los atacadores repite el milagro de las flechas en la leyenda de los santos Cosme y Damián conocida en el ciclo litúrgico mozárabe". Además, el último milagro, el del cataclismo, también tendría un clarísimo origen bíblico (SMITH, 1985, p. 41-42).
} 
Tres siglos después, a finales del siglo XII, el autor de la Crónica Najerense empleará la Crónica de Alfonso III en la composición de su obra, lo que le permitirá integrar el discurso "neogoticista" en el texto ${ }^{35}$. Y es que nuevamente volverá a aparecer la figura de Pelayo y el episodio de Covagonga. De este modo, la conquista musulmana de la Península Ibérica no supondrá el fin del reino visigodo de Toledo, ya que el trono de los godos únicamente permanecerá vacante durante cuatro años, o en palabras del autor, "Y así, muerto Rodrigo, rey de los godos, no hubo reyes godos en esta tierra durante cuatro años" (ESTÉVEZ SOLA, 2003, p. 113). La victoria providencial de Pelayo, "espadero de los reyes Witiza y Rodrigo" (ESTÉVEZ SOLA, 2003, p. 113), permitirá, en palabras del autor, "la salvación de Hispania y que se restituya el ejército del pueblo de los godos" (ESTÉVEZ SOLA, 2003, p. 115). Por lo tanto, el reino Astur y después el reino de León, pero sobre todo la dinastía que los rige, serán continuadores del reino visigodo. Una vez que Pelayo muera le sucederá su yerno Alfonso y de este modo, el nuevo linaje que se instaurará en el trono astur y después en el trono leonés será el legítimo heredero del reino visigodo, puesto que por las venas de sus reyes correrá la sangre de los godos. ${ }^{36}$

\section{El nacimiento de una historiografía castellana: el pensamiento político en la Crónica Najerense}

A lo largo del presente trabajo se ha mencionado con gran insistencia que el principal interés del autor era incorporar el discurso "neogoticista" en la historiografía castellana. A este respecto, el relato legendario que narra la unión entre Sancha y Fernando I tendrá una importancia capital dentro de la obra. Este episodio que, además, está ligado al intento fallido de matrimonio y asesinato del infante García, permitirá “la adopción de Castilla de la tradición goticista, patrimonio exclusivo, hasta ese momento, del reino leonés, construyendo así un gran relato, inédito en la historiografía castellana, que avalará la supremacía de Castilla”, en palabras de Bautista Pérez (2009b).

\footnotetext{
${ }^{35}$ Acerca de la relación entre la Crónica Najerense y la Crónica de Alfonso III consultar: J. A. Estévez Sola (1995b, p. XXIX-XXXIX).

${ }^{36}$ Sin embargo, la obra no presentará ninguna referencia explícita más a la supuesta restauración neogótica, algo que contrastará con su enorme presencia en obras historiográficas contemporáneas, como por ejemplo la Historia Seminensis, que en repetidas ocasiones se referirá a Alfonso VI como: "Alfonso, pues, oriundo de la ilustre prosapia de los godos (...)" (GÓMEZ-MORENO MARTíNEZ, 1921, p. LXVIII). Esta ausencia llevó a algunos autores a cuestionar el supuesto neogoticismo de la obra. A este respecto ver: $\mathrm{H}$. Sirantoine (2009). Esta ausencia se debería explicar muy probablemente por el carácter inacabado de la obra. Además, Le Morvan defiende la utilización de un discurso neogoticista mucho más conceptual y menos explícito. A este respecto ver: G. Le Morvan (2009/2013).
} 
Sancha, hermana del monarca leonés Vermudo III (1028-1037) y portadora, por esa razón, de la regia estirpe de los godos, se casará con Fernando, el segundón de los hijos de Sancho Garcés III (1004-1035), rey de Pamplona, y su mujer, la legítima heredera del conde castellano Sancho y, por lo tanto, del condado de Castilla. La celebración de este enlace va asociada a un hecho de gran relevancia, la sucesión al frente del condado castellano. Y es que una vez que se produce la unión matrimonial entre los cónyuges, Sancho Garcés III entregará el condado de Castilla a su hijo Fernando. De este modo, la naciente dinastía inaugurada por Fernando I estará ligada a la sangre de los godos y el destino de Castilla será, por lo tanto, recuperar los territorios que le habían sido injustamente arrebatados. ${ }^{37}$ El texto najerense pretende construir sobre estos cimientos la legitimidad del nuevo monarca Alfonso VIII, descendiente directo de Fernando I. No obstante, lo más interesante es el relato claramente legendario que construye la Crónica Najerense de este suceso, que servirá en la obra de génesis del reino de Castilla. ${ }^{38}$

Estas dos historias legendarias - la muerte del infante y la boda de Sancha y Fernando- de origen inconexo serán ligadas por el autor. ${ }^{39}$ Esta unión es muy importante, porque dotará al relato de la najerense de unas características propias. La primera de las historias es la de la muerte del infante García, acontecida el mismo día de la celebración de su boda junto a Sancha, la hermana de Vermudo III. El asesinato del infante se producirá a manos de su padrino, el conde Vela, lo que le concederá un gran dramatismo a la narración. La historia procedería de un relato legendario difícil de identificar. Bautista Pérez (2009b) cree

\footnotetext{
${ }^{37}$ La importancia capital de Fernando I en la obra se hace notar, pues el relato que narra su reinado ocupa una extensión considerable, trece de las ciento cuarenta y tres páginas que contiene la obra. Algo que no ocurre con el resto de monarcas. Por ejemplo, el reinado de Alfonso III ocupará tan solo tres páginas; el de Alfonso V ocupará tres páginas; y el de Alfonso VI ocupará cuatro páginas. Esto se podría deber a la función que desempeña Fernando I en el relato, que se podría considerar como el héroe fundador del linaje arquetípico de este tipo de obras. Un personaje fundamental en este tipo de narraciones que tienen "como objeto consolidar su función como fundador y su prestigio como propietario de un condado, asegurando así la continuidad dinástica" (AURELL I CARDONA, 2016, p. 34).

38 Ramos y Loscertales había señalado el papel que jugó la sucesión de Sancho Garcés III en las distintas narraciones historiográficas, un suceso que serviría de génesis de los distintos reinos peninsulares. Ver: J. M. Ramos y Loscertales (1973).

39 Para Bautista Pérez (2009b), la combinación de estas dos historias se habría producido de una manera un tanto precaria, lo que podría evidenciar el carácter inacabado de la obra. Sin embargo, Catalán Menéndez-Pidal cree que estas dos historias procederían de un único relato, un cantar de gesta que denominará: "gesta de los hijos de Sancho el Mayor". Esta tendría como objetivo narrar la sucesión de Sancho Garcés III (CATALÁN MENÉNDEZPIDAL, p. 137-140). La supuesta existencia de este cantar de gesta es muy difícil de demostrar, por lo que parece más razonable pensar que el autor liga dos historias aparentemente diferentes, aunque ambas dotadas de un fuerte carácter legendario-mítico, a las que además añadiría otras noticias posiblemente procedentes de la tradición oral.
} 
que este relato pudo haber sido compuesto en el monasterio de San Salvador de Oña, cenobio en el que se encontraría enterrado dicho infante. El interés del autor por esta historia es, únicamente, para ligarla con la siguiente, la que recoge la boda de Sancha y Fernando, un relato que al igual que el anterior poseería un carácter claramente legendario. Esta última la de la boda de Fernando y Sancha- tendría un origen literario, pues procedería de una narración legendaria aragonesa que relataba la sucesión de Sancho Garcés III. El autor de la najerense la utilizará, aunque la modificará de manera sustancial adecuándola a los intereses de la narración (BAUTISTA PÉREZ, 2009b). ${ }^{40}$ Además, entre estas dos historias el autor introduce una serie noticias nuevamente legendarias/míticas. Así, la narración se presentará como la sucesión de una serie de acontecimientos fortuitos, que, además, guardan una estrecha relación entre sí y que conducen hacía un final esperado. La muerte del infante dejará el condado castellano sin señor, por lo que Sancho Garcés III asumirá el gobierno del señorío, aunque para ello necesitará el beneplácito de los castellanos. Una vez que los castellanos reconocen al monarca de Pamplona, al estar este casado con Urraca, la hija del conde castellano Sancho y hermana del infante asesinado, y, por lo tanto, legitima señora de Castilla, se producirán nuevos acontecimientos. Sancho Garcés III decidirá vengar la muerte del infante asesinado atacando y devastando tierras leonesas, y, finalmente, dará muerte a los asesinos de su cuñado, el conde Vela y sus familiares. A su vuelta se llevará consigo a la infanta leonesa Sancha, a la que decidirá casar con su hijo primogénito Ramiro (1035-1063). La intervención nuevamente de los castellanos, que se opondrán de una manera firme a la unión, al no ser este Ramiro hijo legítimo y, por lo tanto, digno heredero del condado, será determinante para la elección de Fernando. Finalmente, este se casará con la infanta leonesa y recibirá el condado de Castilla.

Para Bautista Pérez el autor se habría valido de una estructura de agravio y reparación, ${ }^{41}$ tratando de sugerir una conexión entre el proyecto frustrado de matrimonio entre el infante castellano asesinado y la infanta leonesa, y el enlace de esta con Fernando. Con ello "dotaba de un sentido providencial al curso de los hechos, y presentaba la emergencia

\footnotetext{
40 Esta narración, en forma de novas rimadas, será empleada nuevamente por el autor del Liber regum y de la Historia Gothica, lo que permitió a Bautista Pérez la reconstrucción del texto original. Este pretendería "ofrecer una fundamentación virtuosa y caballeresca para el nacimiento del reino de Aragón".

${ }^{41}$ A este respecto hay que tener en cuenta la dimensión no solo política del texto historiográfico en la Edad Media, sino que también moral (AURELL I CARDONA, 2013, p. 104).
} 
del reino de Castilla como una forma de renacimiento y de superación histórica" (AURELL I CARDONA, 2013, p. 104). ${ }^{42}$

\section{Conclusiones}

Al inicio del presente trabajo se mencionaron las grandes transformaciones que sufrió la disciplina histórica en las últimas décadas del siglo XX, resultado de la irrupción de la llamada "Posmodernidad". La nueva concepción de la historia resaltó la naturaleza eminentemente narrativa del texto historiográfico, y que el único procedimiento del historiador para recuperar el pasado, para re-presentarlo, era la construcción de un relato. Además, la integración de los distintos acontecimientos históricos en una estructura de trama; la utilización y el recurso permanente del historiador a la denominada "imaginación constructiva" y, por lo tanto, su capacidad para negociar con la ficción, permitirían la asimilación entre la historia y la literatura. Al menos esta similitud entre las dos se produciría a nivel formal, lo que permitió a algunos historiadores la aplicación de teorías literarias al estudio de los textos historiográficos. El ejemplo de Hayden White es un caso paradigmático.

El nacimiento del denominado "nuevo medievalismo" en los años noventa permitiría una reconsideración de las narraciones historiográficas medievales, así como la creación de nuevas metodologías dedicadas a su estudio e interpretación desde nuevos presupuestos. Entre algunos de estos ejemplos se menciona la metodología propuesta por Gabrielle Spiegel, la llamada "lógica social del texto", y su gran utilidad para el estudio de los textos historiográficos medievales. Motivo por el cual se decidió emplearla para el estudio de la Crónica Najerense. Al considerar el texto historiográfico como un artefacto literario, que, además, ocuparía un determinado espacio social, Spiegel plantea que las mutaciones y la adopción de nuevas formas literarias en la historiografía serían el resultado de una serie de transformaciones más profundas.

La adopción de la forma genealógica en las narraciones historiográficas fue el resultado del nacimiento de las distintas monarquías europeas y su definitiva consolidación como una institución dinástica y hereditaria. En el caso del Crónica Najerense, la adopción de

\footnotetext{
42 La historia en la Edad Media poseía claramente un carácter providencial. De este modo, el proceso histórico sería el resultado de un plan divino, la realización providencial del plan que Dios tiene reservado para la humanidad (AURELL I CARDONA, 2013, p. 117). La importancia de la Providencia es tal que Mitre Fernández la consideraba el motor de la historia en la Edad Media (MITRE FERNÁNDEZ, 1982, p. 49).
} 
esta forma estaría relacionada con el desarrollo de la llamada "monarquía feudal" en el reino de Castilla. Asimismo, la necesidad de prestigiar la monarquía castellana y la preeminencia política de su rey frente a sus principales adversarios políticos, así como a legitimar la agresiva actividad militar que este estaba llevando a cabo en la península, llevó muy probablemente a un clérigo najerino a componer esta obra. A través de la utilización de la forma genealógica el autor adoptará la doctrina "neogoticista" en la naciente historiografía castellana. De este modo, la recién fundada dinastía castellana -fundada un siglo antes por Fernando I-gozará de una gran antigüedad, al ser esta portadora de la regia estirpe de los godos. Por lo tanto, el prestigio que le confiere la antigüedad de su linaje resaltará la preeminencia política de Alfonso VIII, fundamentalmente frente a sus principales adversarios. Además, el reino de Castilla, al considerarse heredero del reino Visigodo de Toledo, al igual que había hecho el reino Astur en su día, estaría legitimado a emprender una acción militar permanente que le permitiese engrandecer los dominios territoriales del reino. Esta no solo se limitará contra los musulmanes, sino también contra los cristianos, como se ha visto.

El interés que despierta el relato de la boda entre Fernando I y Sancha no se limita exclusivamente a que permitió integrar la doctrina "neogoticista" en la historiografía castellana, sino que su principal importancia reside en que permite construir un particular relato de naturaleza mitológica que narraría la génesis del reino castellano. La conexión entre las dos historias y la particular disposición de los acontecimientos narrados dota al nacimiento del nuevo reino de un sentido providencial, que representará el posterior ascenso de Castilla como el resultado de un plan que Dios tenía reservado desde su nacimiento.

Para finalizar es necesario destacar la estrecha relación de dependencia entre la política y la historia en la época medieval, la necesidad permanente de legitimación del presente a través del rescate intencional del pasado, una constante que se manifestará en la actividad de los distintos cronistas medievales. Una pesada losa que pesa no solo sobre los historiadores medievales, sino que también sobre los historiadores modernos y posmodernos.

\section{REFERENCIAS BIBLIOGRÁFICAS}

ÁLVAREZ BORGE, Ignacio. La plena Edad Media. Siglos XII y XIII. Madrid: Síntesis, 2010.

ARBESÚ, D. De Pelayo a Belay: la batalla de Covadonga según los historiadores árabes. Bulletin of Spanish Studies, v. LXXXVIII, n. 3, 2011, p. 321-340. 
AURELL I CARDONA, Jaume. El nuevo medievalismo y la interpretación de los textos históricos. HISPANIA. Revista Española de Historia, v. LXVI, n. 224, 2006a, p. 809-832.

. Hayden White y la naturaleza narrativa de la historia. Revista Anuario filosófico, v. 39, n. 87, 2006b, p. 625-648.

. La historiografía medieval: siglos IX-XV. En: AURELL I CARDONA, Jaume; BALMACEDA ERRAZURRIZ, Catalina; BURKE, Peter. Comprender el pasado. Una historia de las escrituras y el pensamiento histórico. Madrid: Akal, 2013, p. 95-141.

. La historiografía medieval. Entre la historia y la literatura. Valencia: Publicacions de la Universitat de València, 2016.

AYALA MARTÍNEZ, Carlos. Realidad y percepción de Hispania en la Edad Media. Revista eHumanista: Journal of Iberian Studies, n. 37, 2017, p. 206-231.

BAUTISTA PÉREZ, Francisco. Sancho Il y Rodrigo Campeador en la Chronica Naierensis. Revista e-Spania (en línea), n. 7, junio, 2009a. Publicado el 21 febrero 2010. URL: http://journals.openedition.org/espania/18101; DOI: 10.4000/e-spania.18101.

. Genealogía y leyenda. El surgimiento de los reinos de Castilla y Aragón. Revista e-Spania (en línea), n. 7, junio, 2009b. Publicado el 16 agosto 2010. URL: http://journals.openedition.org/espania/18086; DOI: 10.4000/e-spania.18086.

BECEIRO PITA, Inés. La conciencia de los antepasados y la gloria del linaje en la Castilla bajomedieval. En: PASTOR DE TOGNERI, Reyna. Relaciones de poder, de producción y parentesco en la Edad Media y Moderna. Madrid: Centro Superior de Investigaciones Científicas, 1990.

BOLAÑOS DE MIGUEL, Aitor Manuel. Historiografía y Postmodernidad: la teoría de la representación de F. R. Ankersmit. Revista Historia y política: Ideas, procesos y movimientos sociales, n. 25, 2011, p. 271-308.

CATALÁN MENÉNDEZ-PIDAL, Diego. La épica española. Nueva documentación y nueva evaluación. Madrid: Fundación Ramón Menéndez Pidal, 2001.

DACOSTA MARTíNEZ, Arsenio. Notas sobre las crónicas ovetenses del siglo IX. Pelayo y el sistema sucesorio en el caudillaje asturiano. Revista Studia Histórica. Historia medieval, n. 10, 1992, p. 9-46.

DUBY, George. Hombres y estructuras en la Edad Media. Madrid: Siglo XXI Editores de España, 1978.

ESTEPA DÍEZ, Carlos. La configuración del reino de Castilla en torno al valle del Duero. Revista Biblioteca: estudio e investigación, n. 24, 2009, p. 37-45.

ESTÉVEZ SOLA, José Antonio. La fecha de la Chronica Naierensis. Revista La corónica, n. 23.2, 1995A, p. 94-103.

ESTÉVEZ SOLA, José Antonio (ed.). Chronica Hispana: saecvli XII. Pars II: Chronica Naierensis. Turnholt, Brepols (Corpus Christianorum. Continuatio Mediaevalis, 81 A), 1995b.

ESTÉVEZ SOLA, José Antonio (ed.). Crónica Najerense. Madrid: Akal, 2003.

GARCÍA DE CORTAZAR Y RUIZ DE AGUIRRE, José Angel. Cultura en el reinado de Alfonso VIII de Castilla: signos de un cambio de mentalidades y sensibilidades en II Curso de Cultura Medieval. Alfonso VIII y se época. Aguilar de Campo. 1-6 octubre 1990. Madrid: Centro de Estudios del Románico, 1992, p. 167194. 
GARCÍA FITZ, Francisco. La Edad Media: guerra e ideología, justificaciones religiosas y jurídicas. Madrid: Silex, 2006.

GÓMEZ-MORENO MARTíNEZ, Manuel. (ed.), Introducción a la Historia Silense con versión castellana de la misma y de la Crónica de Sampiro. Madrid, Junta para Ampliación de Estudios e Investigaciones Científicas, Centro de Estudios Históricos, 1921

GONZÁLEZ GONZÁLEZ, Julio. El reino de Castilla en la época de Alfonso VIII. v. 1. Madrid: Escuela de Estudios Medievales, 1960.

LE GOFF, Jacques. La civilización del occidente medieval. Barcelona: Paidós, 1999.

LE MORVAN, Gael. La Chronica naiarensis: d'un néo-gothisme astur-léonais à un néo-gothisme castillan. Revista e-Spania (en línea), n. 7, junio, 2009. Publicado el 18 diciembre 2013. URL: http://journals.openedition.org/e-spania/18028; DOI: 10.4000/e-spania.18028.

MARTIN, George. Mujeres de la Najerense. Revista e-Spania (en línea), n. 7, junio, 2009. Publicado el 23 febrero 2013. URL: http://journals.openedition.org/e-spania/17990; DOI: 10.4000/e-spania.17990.

MARTÍNEZ DÍEZ, Gonzalo. El condado de Castilla (711-1038). La historia frente a la leyenda. Valladolid: Marcial Pons, 2005.

MENEGELLO MATTE, Raimundo. El discurso político en las crónicas y cronistas de los reinos de Castilla y León. Siglos XII-XIII. Revista Intus-legere: historia, n. 2, 2009, p. 9-27.

MENÉNDEZ PIDAL, Ramón. Relatos poéticos en las crónicas medievales. Nuevas indicaciones. Revista de Filología Española, n. 10, 1923, p. 329-372.

MITRE FERNÁNDEZ, Emilio. Historiografía y mentalidades históricas en la Europa Medieval. Madrid: Editorial de la Universidad Complutense, 1982.

. La España medieval: sociedades, estados y culturas. Madrid: Itsmo, 1999.

. Una primera Europa. Romanos, cristianos y germanos. Madrid: Encuentro, 2009.

MONTENEGRO VALENTín, Julia. Pelayo y Oviedo. Una revisión historiográfica en La época de la monarquía asturiana: actas del simpósio. Covadonga. 8-10 de octubre de 2001. Oviedo: Instituto de Estudios Asturianos, 2002, p. 111-124.

MORADIELLOS GARCÍA, Enrique. El oficio del historiador. Estudiar, enseñar, investigar. Madrid: Akal, 2013.

ORCASTEGUI GRAL, Carmen y SARASA SÁNCHEZ, Esteban. La historia en la Edad Media. Historiografía e historiadores en Europa Occidental: siglos V-XIII. Madrid, Cátedra, 1991.

REGLERO DE LA FUENTE, Carlos María. La Crónica najerense, Santa María de Nájera y Cluny. Revista eSpania (en línea), n. 7, junio, 2009. Publicado el 01 julio 2009. URL: http://journals.openedition.org/espania/18162; DOI: 10.4000/e-spania.18162.

RICOEUR, Paul. Narratividad, fenomenología y hermeneútica. Revista Anàlisi, n. 25, 2000, p. 189-207.

RUIZ GÓMEZ, Francisco. La dimensión bélico-territorial del reinado de Alfonso VIII de Castilla en 1212, un año, un reinado, un tiempo de despegue. XXIII Semana de Estudios Medievales. Nájera, 30 de julio al 3 de agosto, 2012. Logroño: Instituto de Estudios Riojanos, 2013, p. 139-170. 
SMITH, Colin. La creación del Poema de mio Cid. Barcelona: Ed. Crítica, 1985.

SPIEGEL, Gabrielle Michele. History, Historicism, and the Social Logic of the Text in the Middle Ages. Revista Speculum, v. 65, n. 1, 1990, p. 59-86. . The past as text. The Theory and Practice of Medieval Historiography. Balthimore: The Hohns Hopkins University Press, 1997.

UBIETO ARTETA, Antonio (ed.). Crónica Najerense. Valencia: Anubar, 1966. . Crónica Najerense. Zaragoza: Anubar, 1985.

VIÑAYO GONZÁLEZ, Antonio. Fernando I, el Magno. 1035-1065. Burgos: La Olmeda, 1999.

WHITE, Hayden. Metahistoria. La imaginación histórica en la Europa del siglo XIX. México D.F.: Fondo de Cultura Económica, 1992.

. El texto histórico como artefacto literário. En: WHITE, Hayden. El texto histórico como artefacto literario y otros escritos. Barcelona: Paidós, 2003a, p. 107-139.

WHITE, Hayden. La estructura de la narrativa histórica. En: WHITE, Hayden. El texto histórico como artefacto literario y otros escritos. Barcelona: Paidós, 2003b, p. 229-251. 